\title{
AGRICULTURAL ROBOT FOR PLANT HEALTH DETECTION
}

\author{
Kalindi D. Mahajan (Assistant Professor), P.Darunte; B. Borase; R.Bodake (Students) \\ Department of Electronics and Telecommunication \\ MET, Bhujbal Knowledge City, IOE, \\ Nashik, Maharashtra, India
}

\begin{abstract}
It is difficult task for producing agricultural products, various micro-organisms, pests and bacterial diseases attack on plants. These diseases can occur through the leaves, steams or fruit inspection. This paper covers technique of image processing for early detection of plant disease through feature extraction of leaf and preprocessing of image from RGB to different color space conversion, image enhancement; segment the region of interest and minimum distance classifier is used. When plant disease is detected fertilizer motor gets $O N$. The robot has also watering mechanism, it will water the plants according to their needs by observing temperature. Working of the Robot is based on Bluetooth.
\end{abstract}

Keywords: Plant Health, Open Agriculture, Bluetooth, Database.

\section{INTRODUCTION}

Robot uses vision based row guidance method to drive through the row crops. The future of agricultural production deals with robotics and automation which plays important role in our society. As robot plays fundamental role for increase in efficiency and leads to reduction in cost of industrial production and products. Including color, temperature and humidity number of sensors are integrated into robotic system. The system is integrated into automated package. This allows the system to automatically return to specified sites at time intervals [1]. It is use to identify the subtle changes in growth rates and leaf color. It helps us to reduced human input.

\section{NEED OF PAPER}

From the start of human, humans are worked in the farms directly but from the start of 21 st century many industries are worked to reduce this human labor by making robots and machines. Agriculture is very labor intensive field and only field where the robots are not involved mostly [2]. Now-a- days many industries are trying to reduce this human labor by making robots and machines. Currently chemicals are applied to the plants periodically without knowing the requirement of plants. Hence productivity of agriculture decreases.

\section{LITERATURE REVIEW}

Y. Edan, G. E.Miles (Aug, 1994) has proposed System engg. of agricultural robot design paper it presents a systems engineering method to evaluate the performance of an agriculture robot by simulating and comparing different types of robot, number of arms , multiple arm configuration, workspace design and dynamic characteristics. Numerical simulation tool were developed to quantify measures of machine performance such as cycle time and percentage of successful cycles based on an extensive statistical analysis using measured fruit locations and simulated crop parameters.

S.Arima. (1994) has proposed Studies on Cucumber Harvesting Robot Cucumber is widely cultivated fruit vegetable in Japan, and its fruit grows rapidly. In this paper, an automatization of cucumber harvesting system by robot was investigated.

M.Monta, N.Kondo, Y.Shibano (1995) has proposed Agriculture robot in grape production system. A multipurpose agricultural robot which worked in vineyard has been studied. This robot which consisted of a manipulator, a visual sensor, a traveling device and endeffectors was able to several works by changing endeffectors.

TABLE.1. Literature Review [1-13]

\begin{tabular}{|c|c|c|c|}
\hline $\begin{array}{c}\text { Sr. } \\
\text { No. }\end{array}$ & Name of author & Publication Name & Technique Used \\
\hline 1. & $\begin{array}{l}\text { Y. Edan \& G. } \\
\text { E. Miles }\end{array}$ & $\begin{array}{c}\text { IEEE Transaction on system } \\
\text { man \& cybernaticsin, 1994. }\end{array}$ & $\begin{array}{c}\text { Numerical } \\
\text { simulation tool. }\end{array}$ \\
\hline 2. & $\begin{array}{c}\text { S.Arima. } \\
\text { 3. }\end{array}$ & $\begin{array}{c}\text { Mournal of the Japanese } \\
\text { Society of Agricultural } \\
\text { Machinery, 1994. }\end{array}$ & $\begin{array}{c}\text { Robot } \\
\text { kinematics. }\end{array}$ \\
\hline Shibano. & $\begin{array}{c}\text { Robotics and Automation in } \\
\text { 1995. }\end{array}$ & $\begin{array}{c}\text { Robot } \\
\text { kinematics. }\end{array}$ \\
\hline 4. & $\begin{array}{c}\text { Sanjay B. Patil, } \\
\text { Dr. Shrikant K. } \\
\text { Bodhe. }\end{array}$ & $\begin{array}{c}\text { International Journal of } \\
\text { Engineering and } \\
\text { Technology, 2011 }\end{array}$ & $\begin{array}{c}\text { Image } \\
\text { Processing. }\end{array}$ \\
\hline
\end{tabular}


International Journal of Engineering Applied Sciences and Technology, 2019

Vol. 4, Issue 3, ISSN No. 2455-2143, Pages 177-181

Published Online July 2019 in IJEAST (http://www.ijeast.com)

\begin{tabular}{|c|c|c|c|}
\hline & Marcel & IEEE Robotics and & \\
5. & $\begin{array}{c}\text { Bergerman, Eldert } \\
\text { van Henten et.al. }\end{array}$ & $\begin{array}{c}\text { Automation Society } \\
\text { Technical Committee. }\end{array}$ & $\begin{array}{c}\text { Digital } \\
\text { Object } \\
\text { Identifier. }\end{array}$ \\
\hline
\end{tabular}

Sanjay B. Patil, Dr. Shrikant K.Bodhe (2011) has proposed Leaf Disease Severity Measurement. Fungicaused diseases in sugarcane are the most predominant diseases which appear as spots on the leaves. If not treated on time, causes the severe loss.

Marcel Bergerman, Eldert van Henten, John Billingsley, John Reid, and Deng Mingcong (June 2013) has proposed Agricultural Robotics and Automation can play a significant role in society to meet its future agriculture production needs.

\section{BLOCK DIAGRAM}

\section{Leaf Image:}

Plant leaf disease is one of the crucial causes that reduces quantity and degrades quality of the agricultural products. Currently chemicals are applied to the plants periodically without knowing the requirement of plants.

\section{Pre-process:}

Image pre-processing is the lowest level of abstraction whose aim is to improve the image data that suppress undesired distortions as well as enhances some image features which is important for further processing and analysis task. It includes color space conversion and image enhancement.

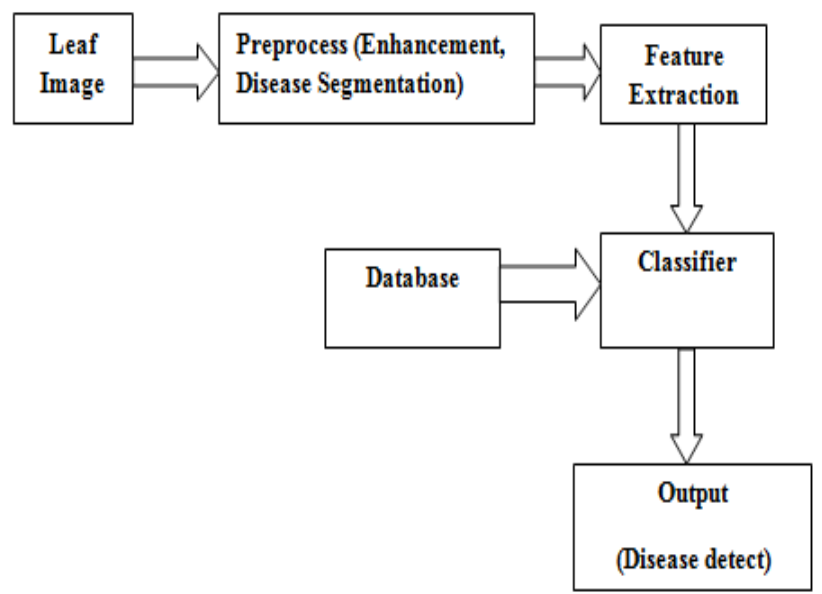

Fig. 1 Block Diagram of Methodology [3]

Image Enhancement:

Direct observation of color images is often strikingly different as human visual perception computes the conscious representation. A simple approach in the block
(DCT) Discrete Cosine Transform domain for enhancing color images by scaling the transform coefficients i.e. color enhancement.

Image Segmentation:

Image segmentation is process used to simplify the representation of an image into something that is more meaningful object of interest from background and easier to analyze. Segmentation is also done through feature based clustering.

\section{Feature Extraction:}

After segmentation the area of interest i.e. diseased part extracted. The aim of this phase is to find and extract features that can be used to determine the meaning of a given sample. Image features usually include color, shape and texture features in image processing. Texture is one of most popular features for image classification and retrieval. Currently most of the researchers targeting plant leaf texture as the most important feature in classifying plants.

\section{Classifier:}

In database minimum five types of disease of data are stored classifier compares these stored data with collected data and detect the diseases. We are using Minimum Distance classifier, for classifying unknown image data to classes which minimize the distance between image data and the class in multi-feature space. Following distances are often used in this procedure are Euclidian Distance, normalized Euclidian distance.

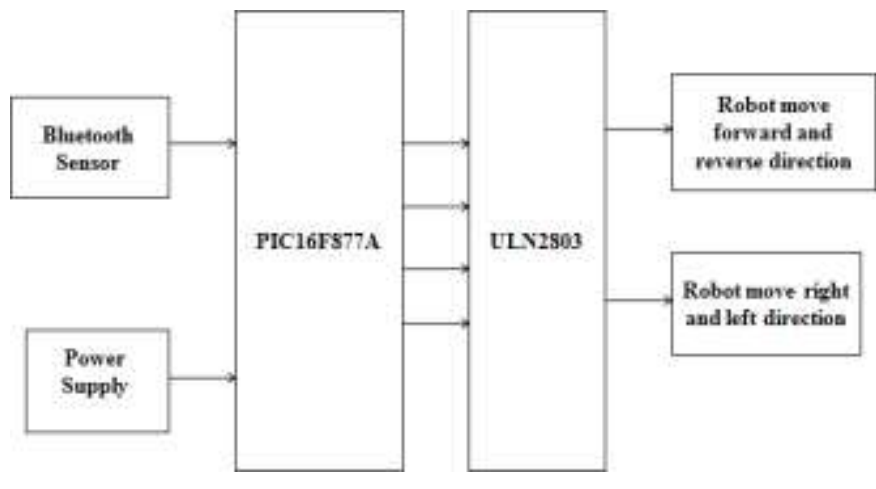

Fig. 2 Block diagram of Robot with Bluetooth sensor [4]

Interfacing of PIC with MATLAB:

Leaf disease is detected using MATLAB software. Output of MATLAB is serially given to PIC microcontroller. Temperature sensor and LCD are interfaced to PIC microcontroller. LM 35 will sense the temperature and display on LCD. ULN 2803 IC is interfaced with PIC microcontroller for current boosting. When Relay1 is ON, water motor gets started. When Relay2 is $\mathrm{ON}$, fertilizer motor gets started. 
International Journal of Engineering Applied Sciences and Technology, 2019

Vol. 4, Issue 3, ISSN No. 2455-2143, Pages 177-181

Published Online July 2019 in IJEAST (http://www.ijeast.com)

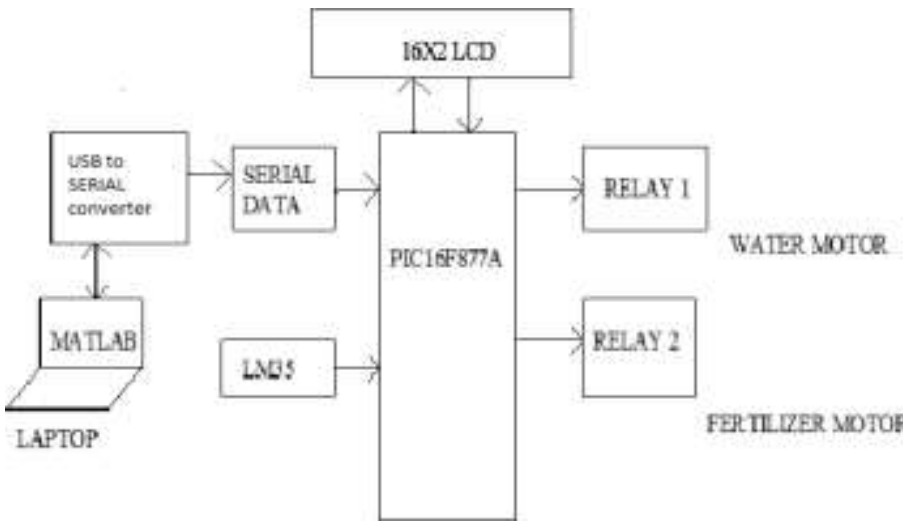

Fig. 3 Block diagram of Interfacing of PIC with MATLAB [5-7] Robot is operated by Bluetooth sensor at a range of $10 \mathrm{~m}$. R1 and R3 ON Robot move forward direction. R2 and R4 ON Robot move reverse direction. Relay 1, Relay 2, Relay 3, Relay 4 are interfaced with IC ULN 2803 current boosting, it consist of Darlington transistor pair. It boost current up to 0.5 to $2 \mathrm{~A}$.

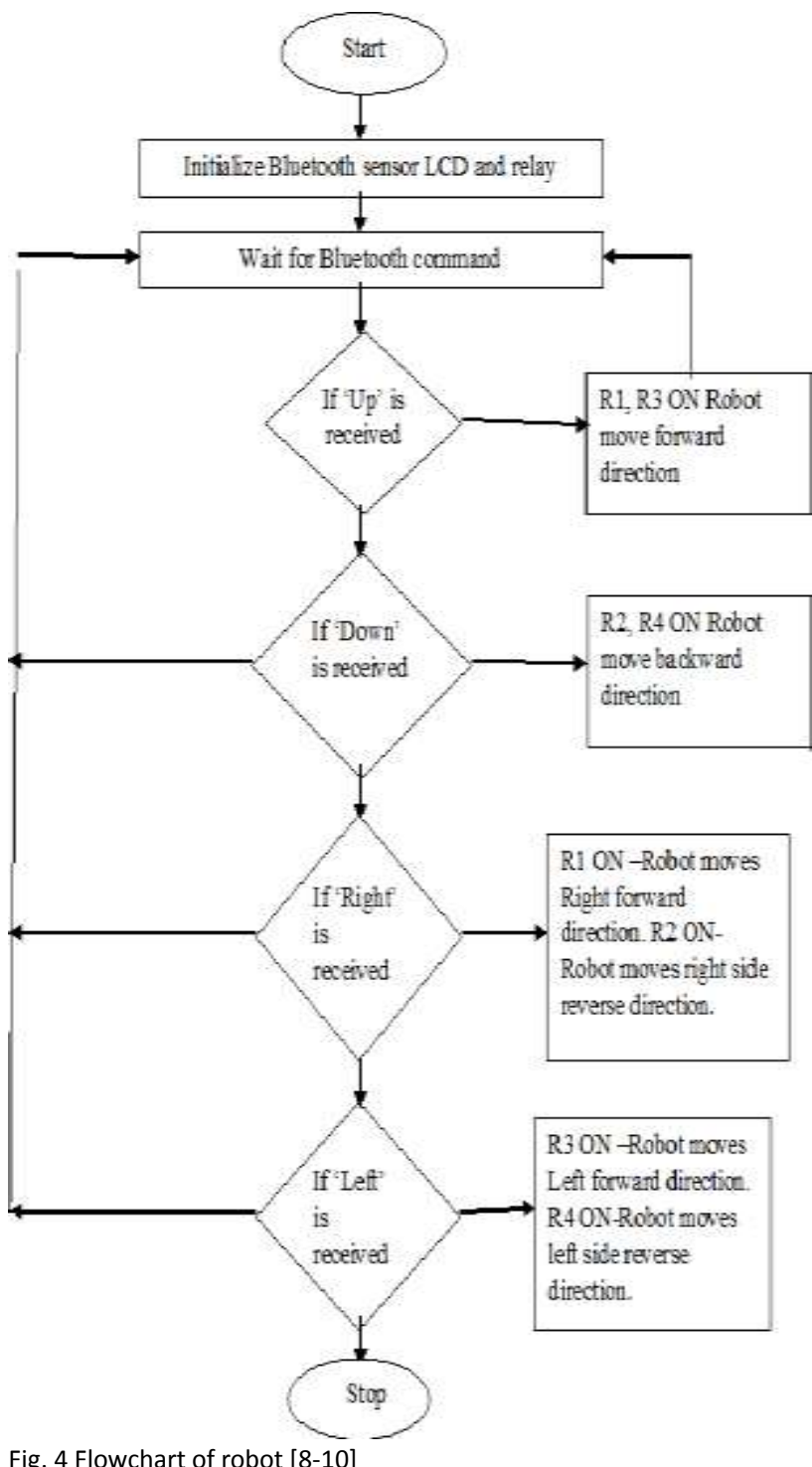

Fig. 4 Flowchart of robot [8-10]
When Relay 1 and Relay 3 ON, Robot moves forward direction. When Relay 2 and Relay 4 ON, Robot moves backward direction. When Relay 1 is ON robot moves to right side forward direction. When Relay 2 is $\mathrm{ON}$ robot moves to right side reverse direction. When Relay 3 is ON robot moves to left side forward direction. When Relay 4 is ON robot moves to left side reverse direction.

\section{SOFTWARES USED}

MPLAB: MPLAB is a free integrated for the development of embedded applications on PIC and ds PIC microcontrollers, and is developed by micro strip technology. MPLAB X is the latest edition of MPLAB, and is developed on the net bean platform. MPLAB and MPLAB X support project management, code editing, debugging and programming of Microchip 8-bit, 16-bit and 32-bit PIC microcontrollers.

MATLAB: The software package has been commercially available since 1984 and is now considered as a standard tool at most universities and industries worldwide. The name MATLAB stands for MATRIX Laboratory. There are toolboxes for signal processing, symbolic computation, control theory, simulation, optimization, and several other fields of applied science and engineering.

\section{ORCAD:}

This document introduces you to a suite of computer programs that are used to design electronic circuits. Cadence ORCAD PCB Designer with P Spice comprises three main applications. $\mathrm{P}$ Spice simulates the captured circuit. ORCAD is available on networked Windows PCs in the department, with up to 30 users at any one time.

\section{ALTIUM:}

Altium Designer is a software package which allows electronic circuit designers to design, draw and simulate electronic circuit boards. Altium is a vastly complex software design suite and these notes are designed to introduce the user to the fundamental principles and tools used throughout the package.

\section{PROTEUS:}

The proteus design suite is proprietary software tool suite use primarily for electronic design automation. The software is used mainly by electronic design engineers and technician to create schematic and electronics prints for manufacturing PCB. 
International Journal of Engineering Applied Sciences and Technology, 2019

Vol. 4, Issue 3, ISSN No. 2455-2143, Pages 177-181

Published Online July 2019 in IJEAST (http://www.ijeast.com)

\section{RESULTS AND DISCUSSION}

Currently most of the researchers targeting plant leaf texture as the most important feature in classifying plants. Fig. 5 shows the feature extraction such as $\mathrm{Cb} \mathrm{Cr}$.

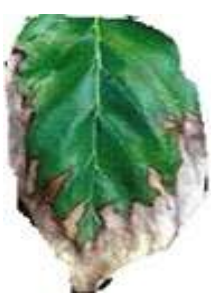

Fig. 5 Input Image

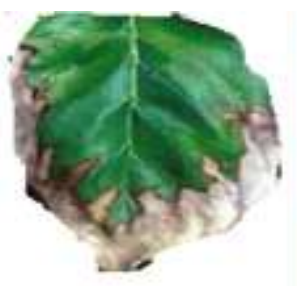

Enhanced Image

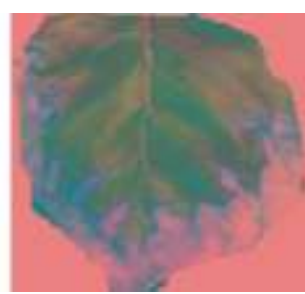

Y Cb Cr Image
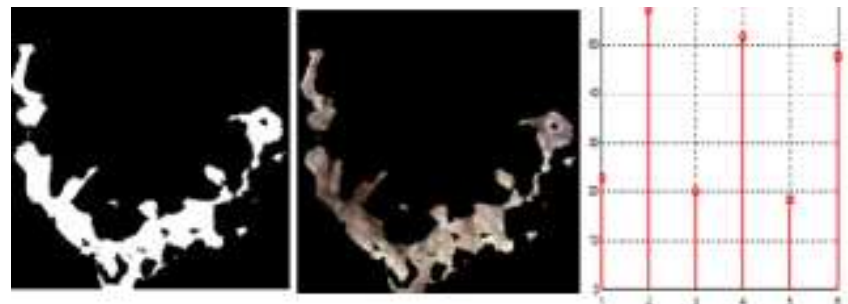

Fig. 6 ROI Image

Diseased Image

Color Moment [11]

The figure 7 shows the complete hardware of the project. On which two tanks are placed one tank is for water and another tank is for fertilizer.

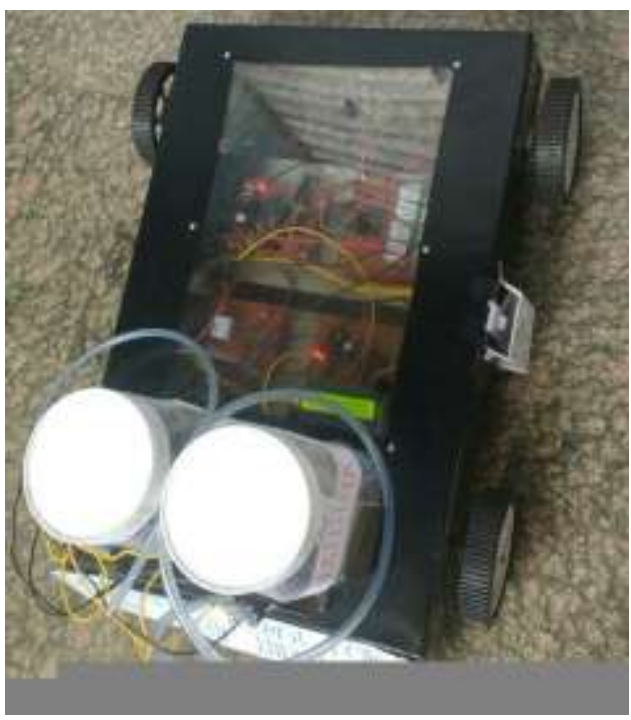

Fig. 7 Manufactured Proposed Robot Hardware [12-13]

Two motors are connected to these two tanks and according to the temperature these motors are ON or OFF.

\section{CONCLUSION}

The proposed system shows how the android Smartphone helps to humans. It gives better result in minimum time using remote controller for robot and various embedded technologies with the help of the Bluetooth technology.

The Wi-Fi wireless networks are used to develop effective remote control program. It has realized that communication between Smartphone and robot is simple and convenient way to control robot. Here the image processing technique is used for feature extraction of disease part of leaf. This system reduces the use of harmful chemicals on plants and it gives us the health environment.

\section{ACKNOWLEDGEMENT}

We would like to place on record our deep sense of gratitude to HOD of Department of Electronics \& Tele Communication Engineering, MET BKC IOE Nasik, for his generous guidance, help and useful suggestions.

We also wish to extend thanks to students and technical assistants for their support and cooperation during fabrication of hardware, we are also thankful to all other staff for their insightful comments and constructive suggestions to improve the quality of this paper.

\section{REFERENCES}

[1] Tillett N.D., Hague T. \& Marchant J.A. (1998). A Robotic System for Plant-Scale Husbandry; in Journal of Agricultural Engineering Research.

[2] Hollingum Jack (1999). Robots in Agricultural; in Industrial Robot.

[3] Sokefeld M., Gerhards Roland \& Kuhbauch W(2000). Site-specific weed control - from weed recording to herbicide application; in Journal of Plant Diseases and Protection.

[4] Sorensen Claus G., Madsen Niels A. \& Jacobsen Brian H. (2005). Organic Farming Scenarios: Operational Analysis and Costs of implementing Innovative Technologies; in Biosystems Engineering.

[5] Blackmore Simon, Stout Bill, Wang Maohua et.al. (2005). Robotic Agriculture-The Future of Agricultural Mechanization; in 5th European Conference on Precision Agriculture Uppsala, Sweden.

[6] Pedersen S.M., Blackmore B. Simon (2006). Agricultural Robots-System Analysis and economic feasibility; in Precision Agriculture.

[7] Mario M. F. and Giulio R. (2006). Agricultural Robot for Radicchio Harvesting; in Journal Of Field Robotics.

[8] Belforte G., Deboli R., Gay P. And Aimonino D. Ricauda (2006). Robot Design And testing For Greenhouse Applications; in Biosystems Engineering.

[9] Patil Sanjay B. (2011). Leaf Disease Severity Measurement Using Image Processing; in International Journal of Engineering and Technology.

[10] Kulkarni Anand H., Patil Ashwin (2012). Applying Image Processing Technique To Detect Plant Diseases; in International Journal of Modern Engineering Research.

[11] Dhaygude Sanjay B., Kumbhar Nitin P. (2013). 
International Journal of Engineering Applied Sciences and Technology, 2019

Vol. 4, Issue 3, ISSN No. 2455-2143, Pages 177-181

Published Online July 2019 in IJEAST (http://www.ijeast.com)

Agricultural Plant Leaf Disease Detection Using Image processing; in International journal of Advanced Research in Electrical, Electronics and Instrumentation Engineering.

[12] Gholap Dipak, More Vaibhav Mhatardev, Lokhande Manojkumar Shrihari (2014). Robotic Agriculture Machine; in International journal of Innovative research in Science, Engineering and Technology.

[13] Fale K.V. , Bhure Amit P. et.al,(2015). Autonomous Farming Robot with Plant Health Indication; in International journal of advanced technology in Engineering and Science. 